\title{
Efektivitas Pembelajaran Bahasa Indonesia Menggunakan Pendekatan Student Active Learning di Jurusan Manajemen Fakultas Ekonomi dan Bisnis Uin Syarif Hidayatullah Jakarta
}

\section{Syihaabul Hudaa}

STIE Ahmad Dahlan, Jakarta

hudaasyihaabul@gmail.com

syihaabul.hudaa@uinjkt.ac.id

\begin{tabular}{ll}
\hline Informasi artikel & \\
\hline Sejarah artikel: & \\
Diterima & I4-09-20I7 \\
Revisi & 28-03-2018 \\
Dipublikasikan & Mei 20I8
\end{tabular}

\section{Kata kunci:}

efektivitas pembelajaran

student active learning

manajemen UIN Jakarta

\begin{abstract}
ABSTRAK
Bahasa Indonesia merupakan mata kuliah wajib yang diambil oleh setiap mahasiswa dalam persyaratan menulis karya ilmiah berupa skripsi. Kemampuan menulis siswa yang rendah, menjadi perhatian segala pihak, khususnya dosen bahasa Indonesia. Dalam upaya mengefektifkan pembelajaran bahasa Indonesia, peneliti menggunakan pendekatan student active learning yang menekankan pada keaktifan siswa di kelas. Pendekatan ini mewajibkan siswa untuk berinteraksi dalam proses pembelajaran. Selain aktif berinteraksi, pendekatan ini mewajibkan siswa kritis terhadap masalah yang muncul di dalam pembelajaran di kelas. Tujuan penulisan artikel ini adalah untuk mengkaji pembelajaran bahasa Indonesia yang dilakukan di kelas Manajemen di UIN Syarif Hidayatullah dengan menggunakan pendekatan student active learning. Melalui pendekatan student active learning yang diujikan oleh peneliti di kelas Manajemen A dan B di Fakultas Ekonomi dan Bisnis UIN Syarif Hidayatullah Jakarta, peneliti mendapatkan hasil yang memuaskan di kelas A, dan hasil yang baik di kelas B. Rata-rata nilai UTS kelas A adalah 83,I4 (A), nilai rata-rata UTS kelas B adalah 72 (B). Nilai rata-rata UAS kelas A adalah 80,4 (A), dan nilai rata-rata UAS kelas B adalah 78,43 (B). Nilai rata-rata formatif +tugas kelas A adalah 82 (A), dan nilai rata-rata formatif+tugas kelas B adalah 77,I (B).
\end{abstract}

Key word:

The affectivity of learning process student active learning management of UIN Jakarta

\begin{abstract}
Indonesian language is a must subject that all of the university student should be taken in term of their final task, which is scientific work, named skripsi. The lecturer of Indonesian language has concern in term of the lack of written ability that the university students nowadays have. The researcher's effort in the affectivity of Indonesian language learning by using student active learning method, which is the emphasize of student activity in the classroom. This method requires student to interact in the learning process. Beside that, student should also have criticism to the problem that might be happen in the classroom's learning process. The purpose of writing this article is to examine the learning of Indonesian conducted in the Management class in UIN Syarif Hidayatullah by using student active learning. Through the method of student active learning that has been examined by the researcher in the Management classroom A and B in Economic and Business Faculty of UIN Syarif Hidayatullah Jakarta, the researcher has the satisfactory result in the Management classroom A, and the unsatisfactory result in the Management classroom $\mathrm{B}$. The average score of mid-semester test of the Management classroom A is 83,I4 (A), The average score of mid-semester test of the Management classroom B is 72 (B). The average score of final-semester test of the Management classroom A is 80,4 (A) The average score of finalsemester test of the Management classroom B is 78,43 (B). The average score of formative and daily tasks of the Management classroom A is $82(\mathrm{~A})$, and the average score of formative and daily tasks of the Management classroom B is $77,1(B)$.
\end{abstract}




\section{Pendahuluan}

Bahasa Indonesia merupakan bahasa nasional yang mengandung unsur budaya di dalamnya (Fitriyah dkk, 2009). Sebagai bahasa nasional, artinya bahasa Indonesia wajib digunakan di seluruh pelosok negara Indonesia sebagai bahasa pemersatu bangsa. Selain sebagai suatu ilmu pengetahuan, fungsi bahasa Indonesia sudah tercantum di dalam UndangUndang Republik Indonesia Nomor 24 Tahun 2009 tentang Bendera, Bahasa, Lambang Negara dan Lagu Kebangsaan (Hudaa, 2017). Pengimplementasian ini bertujuan untuk menanamkan nilai kecintaan terhadap bangsa dan bahasa Indonesia. Sebagai suatu budaya, bahasa tentu saja memiliki ciri yang tidak dimiliki oleh bahasa lainnya. Penggunaan bahasa Indonesia perlu ditekankan, khususnya di negara Indonesia itu sendiri.

Bahasa Indonesia merupakan bahasa nasional yang harus dikuasai dengan baik oleh setiap orang Indonesia. Beberapa orang mengatakan bahwa bahasa Indonesia jinak-jinak merpati. Istilah ini muncul mengingat kesulitan yang terdapat di dalam kaidah penulisan bahasa Indonesia. Kesulitan ini karena banyak pemelajar bahasa Indonesia yang masih menganggap sepele bahasa Indonesia dan lebih bangga berbahasa asing. Misalnya saja dalam ujian nasional nilai yang terendah selalu nilai bahasa Indonesia. Nilai tertinggi untuk bahasa Indonesia pun hanya 7,40 paling rendah dibandingkan nilai lainnya (Kompas, 20I0). Selain itu, fenomena copy dan paste menjadi suatu masalah yang perlu penanganan khusus. Masalah ini muncul karena minat membaca siswa yang rendah, sehingga mereka memilih jalan pintas (Hidayat dkk, 2016).

Pemelajaran bahasa Indonesia penting disadari oleh generasi muda sebagai suatu bentuk kecintaan terhadap negara Indonesia. Akan tetapi, generasi muda terkadang salah memaknai perkembangan zaman. Mereka yang hidup di era modern justru lebih dominan menggunakan bahasa asing. Padahal, bahasa Indonesia mengalami pemutakhiran dalam kaidah yang berlaku di dalamnya. Selain itu, bahasa Indonesia memutakhirkan padanan kata dalam bahasa asing sebagai bentuk bahasa yang terus berkembang yang dapat digunakan generasi muda untuk berkomunikasi.

Muliastuti (2017) bahasa Indonesia dapat dikatakan sebagai bahasa kedua, apabila siswa tersebut mempelajarinya di Indonesia, dengan BI bahasa daerah. Bahasa Indonesia juga dapat menjadi bahasa asing, yang dipelajari di luar negeri dengan BI nya bahasa ibu di negaranya. Permasalahan bagi siswa yang berada di Indonesia, adalah rendahnya minat mempelajari bahasa Indonesia. Rendahnya nilai bahasa Indonesia dibuktikan berdasarkan nilai bahasa Indonesia yang berada di bawah nilai mata pelajaran lainnya. Bukan hanya di sekolah saja, nilai rendah pun terjadi pada mata kuliah bahasa Indonesia di universitas. Padahal, bahasa Indonesia digunakan sebagai dasar penyusunan karya tulis ilmiah siswa di tingkat universitas.

Salah satu contoh kasus yang banyak terjadi dalam ranah akademisi, adalah mahasiswa tidak mampu membedakan teknik penulisan catatan kaki, dengan daftar pustaka. Sering kali disamakan antara penulisan catatan kaki dengan daftar pustaka. Hal ini tentu saja menyalahi kaidah penulisan notasi ilmiah yang benar. Selain catatan kaki dan daftar pustaka, masih ada catatan badan yang harus diketahui mahasiswa sebagai bentuk kemampuan penulisan ilmiah. Permasalahan inilah yang kemudian muncul sebagai suatu masalah bagi akademisi. Mahasiswa dituntut untuk mampu berbahasa Indonesia dengan baik dan benar. Selain itu, pembelajaran bahasa Indonesia di tingkat universitas, menekankan pada aspek kemampuan penulisan ilmiah.

Penelitian ini memfokuskan pada kemampuan siswa dalam menulis ilmiah, berupa makalah dan tugas akhir berupa penelitian yang menganalisis kesalahan penulisan dalam skripsi. Penelitian ini dilakukan dalam waktu 4 bulan, yaitu dari MaretJuni 2017 dengan fokus pada kelas Manajemen A dan B di Fakultas Ekonomi dan Bisnis UIN Syarif Hidayatullah Jakarta. Peneliti menggunakan cara pembelajaran student active learning, yaitu menuntut siswa aktif, baik dalam sesi diskusi, maupun saat dosen menjelaskan.

Munir (2008) mengatakan bahwa student active learning menekankan pada aktivitas siswa untuk lebih aktif dalam kegiatan belajar. Keaktifan ini bisa dalam bentuk kemampuan siswa merespon materi yang diberikan oleh guru atau dosen ketika berada di dalam kelas. Dalam kegiatan pembelajaran aktif, siswa nantinya akan diminta menganalisis masalah, mengemukakan pendapatnya, dan membuat suatu simpulan dalam pembelajaran.

Pendekatan pembelajaran aktif bukanlah suatu hal yang baru dalam kegiatan pembelajaran. Pendekatan ini sudah digunakan sejak era Socrates dan menekankan pada konsep pendidik yang progresif. Pembelajaran aktif yang ditekankan pada pemelajar lebih bersifat alami, sehingga siswa lebih aktif dalam kegiatan berpikir. Jhon Dewey (dalam Arends, 200I: 353) menjelaskan bahwa dalam pengajaran ada beberapa hal yang membantu siswa dalam proses berpikir dan menghasilkan keterampilan yang disebut reflektif thinking. Dengan demikian, Dewey memaknai bahwa proses kognitif 
akan terbentuk saat siswa terlibat dalam kegiatan pembelajaran aktif.

Pembelajaran aktif dimaksudkan untuk menjaga agar siswa tetap fokus dalam kegiatan pembelajaran di kelas. Kegiatan pembelajaran aktif ini menekankan pada proses pembelajaran dan menekankan pada kemampuan menganalisis siswa. Peserta didik akan diminta aktif dalam merespon materi ajar yang diberikan oleh pengjar selama di dalam kelas. Dalam pembelajaran aktif, siswa juga akan diminta mengeksplorasi nilai-nilai yang terdapat di dalam materi pembelajaran. Selain itu, siswa harus mampu mengevaluasi dan memberikan masukan dalam kegiatan pembelajaran di kelas.

Dalam kegiatan pembelajaran aktif, seorang pengajar akan mengaitkan materi yang baru dengan materi yang sebelumnya. Hal tersebut dilakukan dalam upaya mengingatkan siswa akan materi yang sudah berlalu. Kegiatan pembelajaran ini akan mendidik peserta didik memiliki motivasi yang tinggi dalam belajar (Mulyasa, 2004). Untuk itu, pendekatan student active learning dianggap mampu memotivasi siswa dalam mempelajari bahasa Indonesia sebagai dasar dalam menyusun karya ilmiah. Selain itu, penggunaan pendekatan ini diharapkan mampu membuat pemelajar semakin aktif dalam aktivitas pembelajaran.

Tujuan penelitian ini adalah melihat efektivitas pembelajaran bahasa Indonesia di Jurusan Manajemen. Pembelajaran yang dilakukan sebelumnya hanya menggunakan metode diskusi tanpa menenkankan siswa wajib aktif berpastisipasi dalam kegiataan pembelajaran. Akibatnya, mahasiswa terkadang menjadi introver dan sulit mengemukakan pendapatnya di depan umum. Kegiatan pembelajaran aktif sebagai inovasi dalam pembelajaran berupaya mengembangkan keterampilan berbicara mahasiswa di depan umum. Selain itu, kegiatan pembelajaran aktif mengembangkan kemampuan mahasiswa dalam berpikir.

Melalui pendekatan pembelajaran aktif, peneliti mengharapkan adanya peningkatan yang signifikan dari pembelajaran sebelumnya. Hal ini dilakukan untuk mengoptimalisasikan pembelajaran bahasa Indonesia sebagai mata kuliah dasar umum. Melalui pendekatan aktif, mahasiswa yang sebelumnya sulit mengemukakan gagasannya, menjadi mudah dalam menyampaikan gagasannya. Selain itu, penelitian ini bisa menjadi evaluasi untuk dosen bahasa Indonesia dalam upaya meningkatkan kualitasnya sebagai pengajar bahasa.

\section{Metode}

Penelitian ini tergolong penelitian tindakan. Emzir (2007) penelitian tindakan merupakan suatu hal yang paling sesuai untuk para partisipan yang mengenali eksistensi kekurangan dalam aktivitas pendidikan mereka dan yang bermaksud mengadopsi beberapa pendirian awal yang berhubungan dengan masalah, merumuskan rencana, melaksanakan intervensi, dan mengevaluasi. Dengan kata lain, penelitian tindakan mampu menjadi evaluasi bagi pengajar dan pemelajar dalam kegiatan pembelajaran.

Tahapan pembelajaran aktif yang dilakukan oleh peneliti adalah membentuk diskusi kelompok terpumpun dengan posisi duduk melingkar dan pembicara berada di tengah. Setelah itu, presentasi di kelas mahasiswa diwajibkan bertanya dan menanggapi setiap kegiatan diskusi yang dilakukan. Apabila ada mahasiswa yang tidak aktif di kelas, maka ketua mahasiswa akan menginformasikan kepada dosen nama mahasiswa tersebut. Mahasiswa yang kurang aktif akan mendapatkan stimulus dari dosen agar aktif berpartisipasi di kelas.

Pengambilan data dilakukan oleh peneliti melalui pembelajaran aktif yang dilakukan dari bulan Maret-Juni. Peneliti masuk kelas dan memberikan materi bahasa Indonesia yang nantinya akan dilakukan tes di akhir pertemuan. Tes yang dilakukan oleh peneliti dilakukan dalam dua tahap, yaitu UTS dan UAS. Data yang sudah didapatkan oleh peneliti akan dihitung dan dinilai rata-ratanya. Setelah mendapatkan data rata-rata nilai ujian mahasiswa, peneliti akan menjabarkan hasil penelitian secara deskriptif. Hasil inilah yang nantinya akan disimpulkan peneliti untuk menilai keefektivitasan pembelajaran di kelas.

Bagan I. Alur Penelitian

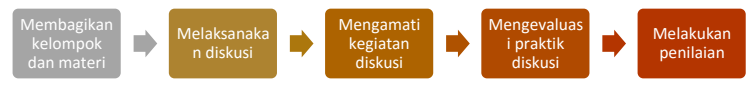

\section{Hasil dan pembahasan}

Pembelajaran bahasa Indonesia memerlukan strategi pembelajaran yang tepat agar materi yang ingin disampaikan dapat tersampaikan dengan baik. Keefektivitasan pembelajaran bahasa Indonesia ditentukan dari kemampuan berbahasa mahasiswa di kelas. Hal tersebut dapat diukur dengan kemampuan mahasiswa saat berada di kelas melalui diskusi dan nilai mahasiswa yang didapatkan dari tes yang diberikan. Salah satu cara mengukur keefektivitasan pembelajaran yang dilakukan oleh mahasiswa adalah melalui nilai rata-rata yang didapatkan. 
Penelitian ini dilakukan pada bulan MaretJuni 2017. Tahapan yang dilakukan oleh peneliti adalah masuk ke dalam kelas, mulai dari membuat kontrak perkuliahan, kesepakatan RPS, dan kesepakatan dalam kegiatan pembelajaran. Data penelitian diperoleh dari dua kelas yang diampu oleh peneliti, yaitu kelas Manajemen A dan B di Fakultas Ekonomi dan Bisnis UIN Syarif Hidayatullah Jakarta. Peneliti mengamati kegiatan belajar-mengajar selama di kelas, dan melakukan evaluasi melalui tes yang diberikan.

Selama melakukan penelitian, peneliti menemukan beberapa hal yang menarik untuk dikaji. Mereka yang berada di dua kelas yang berbeda, ternyata memiliki motivasi belajar yang berbeda. Kelas A sangat antusias dalam mengikuti pembelajaran, sedangkan kelas B tidak terlalu tertarik dalam mengikuti perkuliahan bahasa Indonesia. Mereka yang berada di kelas A, lebih aktif dalam mengikuti pembelajaran dibandingkan dengan kelas B.

Peneliti mengamati perbedaan yang terjadi di dalam kegiatan pembelajaran. Kelas A kondusif, dan mahasiswa memiliki motivasi belajar yang tinggi. Mereka yang berada di kelas A, akan termotivasi oleh teman lainnya untuk aktif dalam berdiskusi selama kegiatan belajar-mengajar. Akan tetapi, berbeda halnya dengan mereka yang berada di kelas B. Mahasiswa di kelas B, didominasi oleh mahasiswa pria yang sering kali mengobrol di kelas. Hal ini mengakibatkan, mahasiswa yang rajin terbawa suasana lingkungan mereka.

Penelitian ini memfokuskan pada hasil karya tulis ilmiah siswa yang nantinya akan dimasukkan ke dalam nilai formatif. Tugas akhir berupa pembuatan analisis kesalahan penulisan yang terdapat di dalam skripsi mahasiswa di FEB UIN Jakarta. Mahasiswa yang sudah melalui tatap muka sebanyak I4 kali, dan mereka bebas menentukan analisis terkait materi yang sudah dipelajari. Tugas akhir ini berbentuk makalah, yang menekankan pada aspek kalimat, paragraf, notasi ilmiah, dan analisis yang dilakukan oleh mahasiswa.

Sebagai bahan analisis, sila diperhatikan data di bawah ini. Data ini terdiri dari hasil UTS Manajemen A dan Manajemen B. Nilai ini merupakan nilai murni yang hanya dikelola hingga memperoleh rata-ratanya. Melalui nilai rata-rata ini, kita dapat melihat perbedaannya.

Tabel I. Hasil rata-rata UTS Manajemen A

\begin{tabular}{|l|l|l|}
\hline Nilai Total & Jumla & Rata-Rata \\
& Mahasiswa & \\
\hline
\end{tabular}

\begin{tabular}{|l|l|l|}
\hline 3575 & 43 & $83, \mathrm{I} 4$ \\
\hline
\end{tabular}

Tabel 2. Hasil rata-rata UTS Manajemen B

\begin{tabular}{|c|c|c|}
\hline Nilai Total & $\begin{array}{l}\text { h Jumla } \\
\text { Mahasiswa }\end{array}$ & \\
\hline 295I & $4 \mathrm{I}$ & 72 \\
\hline
\end{tabular}

Terdapat perbedaan yang signifikan antara kelas A dan B. Nilai di kelas A jauh lebih baik dibandingkan dengan nilai di kelas B. Peneliti mengevaluasi perbedaan nilai yang dianggap terlalu jauh oleh peneliti. Simpulan evaluasi yang dilakukan oleh peneliti adalah tingkat motivasi belajar siswa. Kelas A cenderung lebih aktif dalam kegiatan diskusi, sedangkan kelas B cenderung lebih pasif dalam diskusi. Selain itu, di kelas B ada salah satu mahasiswa yang tidak datang saat ujian tengah semester, dan tidak mengikuti ujian susulan.

Kemampuan berbahasa siswa terlihat jelas dari kedua perbandingan di atas. Kelas A dapat dikatakan sebagai kelas yang memiliki siswa yang aktif dan mengimplementasikan kemampuannya dalam menulis. Sebaliknya, kelas B memiliki nilai yang lebih rendah dari kelas A dan dapat dikatakan sebagai kelas yang tidak mengimplementasikan kemampuannya dalam menulis dengan baik. Siswa kelas A dalam praktik menulis tentu tidak kesulitan dalam membuat karya tulis, karena mahasiswa di kelas A memiliki kemampuan menulis yang baik yang didapatkan dari kegiatan pembelajaran di kelas.

Secara keseluruhan, selama tatap muka ke-7 di kelas A dan B, peneliti menyimpulkan bahwa keaktifan siswa selama di kelas, mampu membuat siswa mampu mengerjakan tugas UTS dengan baik. Berdasarkan evaluasi yang dilakukan oleh peneliti, siswa di kelas B perlu mendapatkan motivasi lebih, sehingga mereka akan mengalami kemajuan dalam tatap muka selanjutnya. Untuk itu, dalam pembelajaran di kelas setelah UTS, peneliti akan menerapkan perhatian khusus kepada siswa yang belum pernah aktif berbicara, baik dalam sesi diskusi, maupun tanya jawab.

Tabel 3. Hasil rata-rata UAS Manajemen A

\begin{tabular}{|l|c|c|}
\hline Nilai Total & $\begin{array}{l}\text { h Jumla } \\
\text { Mahasiswa }\end{array}$ & \\
\hline 3375 & 42 & 80,4 \\
\hline
\end{tabular}

Tabel 4. Hasil rata-rata UAS Manajemen B 


\begin{tabular}{|l|c|c|}
\hline Nilai Total & $\begin{array}{l}\text { h Jumla } \\
\text { Mahasiswa }\end{array}$ & Rata-Rata \\
\hline 2745 & 35 & 78,43 \\
\hline
\end{tabular}

Dapat dilihat dari rata-rata nilai UAS kelas A dan B, sudah mengalami perubahan yang signifikan. Akan tetapi, muncul kendala baru, di mana ada mahasiswa yang tidak mencapai tatap muka sebesar $75 \%$ atau maksimal 3 kali tidak hadir. Jika mahasiswa tidak hadir lebih dari 4 kali, dan tanpa keterangan, maka mahasiswa tersebut tidak bisa mengikuti ujian akhir semester. Selain itu, mahasiswa tersebut akan mendapakan nilai formatif sebatas mengikuti perkuliahan saja, karena mahasiswa tersebut tidak mengumpulkan tugas akhir berupa penulisan makalah ilmiah.

Dalam kegiatan belajar aktif, mahasiswa diwajibkan mengikuti aturan yang sudah disepakati di awal perkuliahan. Sanksi bagi mahasiswa yang melanggar sudah disepakati, dan tidak diperkenankan siswa yang tidak hadir melebihi 3 kali tanpa keterangan, untuk mengikuti ujian akhir semester. Selain mengajarkan keaktifan di kelas, pembelajaran aktif mendidik siswa untuk bersikap disiplin dalam kegiatan pembelajaran. Untuk itu, pemberian sanksi ini bertujuan untuk mengubah sikap mahasiswa ke depannya, agar menaati peraturan yang sudah dibuat di dalam kelas.

Penilaian terakhir berkaitan dengan output atau luaran pembelajaran bahasa Indonesia, adalah pemberian tugas akhir berupa penulisan karya ilmiah berupa makalah. Makalah yang dibuat oleh mahasiswa merupakan hasil penelitian mereka. Mereka mengimplementasikan materi pembelajaran yang sudah dipelajari ke dalam penelitian mereka. Penelitian ini bisa memilih tema bebas, dengan acuan materi pembelajaran yang sudah dipelajari selama perkuliahan di kelas. Mahasiswa diminta untuk berpikir kritis dalam menganalisis, selain itu, pemilihan tema akan membuat mahasiswa fokus dalam melakukan analisis. Dengan adanya tugas individu ini, mahasiswa nantinya akan mengembangkan pola pikir dalam membuat sintesis, dan juga analisis pembahasan penelitian.

Tabel 5. Hasil rata-rata Formatif+Tugas Individu Manajemen A

\begin{tabular}{|l|l|l|}
\hline Nilai Total & $\begin{array}{l}\text { humla } \\
\text { h }\end{array}$ & Rata-Rata \\
& Mahasiswa & \\
\hline
\end{tabular}

\begin{tabular}{|l|l|l|}
\hline 3443 & 42 & 82 \\
\hline
\end{tabular}

Tabel 6. Hasil rata-rata Formatif+Tugas Individu Manajemen B

\begin{tabular}{|c|c|c|}
\hline Nilai Total & $\begin{array}{l}\text { h Jumla } \\
\text { Mahasiswa }\end{array}$ & Rata-Rata \\
\hline 3I6I & $4 \mathrm{I}$ & $77, \mathrm{I}$ \\
\hline
\end{tabular}

Berdasarkan nilai tugas yang digabungkan dengan nilai keaktifan di kelas, hasil yang diperoleh sudah sampai pada tahap memuaskan untuk kelas A dan predikat baik untuk kelas B. Nilai yang diperoleh merupakan hasil dari nilai tugas individu mahasiswa dalam pembuatan makalah individu, ditambah dengan nilai formatif (kehadiran, dan keaktifan) selama di kelas.

Nilai di atas tidak sepenuhnya maksimal di kelas A dan B, karena ada beberapa mahasiswa di kelas yang tidak membuat tugas individu, sehingga mereka hanya mendapatkan nilai formatif saja. Selain itu, saat dilakukan tanya jawab dalam presentasi hasil penelitian, ada beberapa siswa yang tidak mampu menjawab pertanyaan seputar penelitian mereka. Hal tersebut dikarenakan siswa lupa dan ada yang menjawab asal saja, sepengetahuannya saja.

Dari penelitian yang dilakukan oleh peneliti selama 4 bulan, nilai rata-rata yang diperoleh, baik dalam UTS, UAS, dan Formatif tidak ada yang mendapatkan rata-rata di bawah 70. Standardisasi untuk mata kuliah bahasa Indonesia adalah B, atau dengan angka 70. Jika mahasiswa mendapatkan nilai di bawah 70, artinya mahasiswa tersebut harus mengulang mata kuliah bahasa Indonesia di semester berikutnya.

\section{Simpulan}

Berdasarkan penelitian yang dilakukan oleh peneliti, dapat disimpulkan bahwa pembelajaran bahasa Indonesia menggunakan pendekatan student active learning 'efektif diterapkan di dalam kelas Manajemen A dan B di Fakultas Ekonomi UIN Syarif Hidayatullah jakarta. Nilai rata-rata UTS kelas A adalah 83,I4 (A), nilai rata-rata UTS kelas B adalah 72 (B). Nilai rata-rata UAS kelas A adalah 80,4 (A), dan nilai rata-rata UAS kelas B adalah 78,43 (B). Nilai rata-rata formatif + tugas kelas A adalah 82 (A), dan nilai rata-rata formatif + tugas kelas B adalah 77,I (B). 
Dengan demikian dapat disimpulkan bahwa dari ketiga rata-rata nilai yang sudah dianalisis oleh peneliti, tidak ada satu pun rata-rata yang dibawah 70. Untuk itu, dapat disimpulkan bahwa pembelajaran bahasa Indonesia di kelas Manajemen A dan B efektif menggunakan pendekatan student active learning. Peneliti akan melakukan evaluasi dalam penelitian selanjutnya, dengan cara menanamkan pembekalan motivasi untuk aktif berpartisipasi dalam kegiatan belajar mengajar. Selain itu, peneliti akan menekankan aspek kehadiran, agar semua siswa yang mengikuti kegiatan pembelajaran di kelas dapat mengikuti ujian akhir semester.

\section{Persantunan}

Artikel ini disusun atas dorongan dan dukungan dari berbagai pihak. Ucapan terimakasih disampaikan kepada Ketua dan Sekretaris Program Studi Pendidikan Bahasa dan Sastra Indonesia STIE Ahmad Dahlan dan teman-teman sejawat. Ucapan terima kasih juga disampaikan kepada tim editorial Bahastra Pendidikan Bahasa dan Sastra Indonesia Universitas Ahmad Dahlan yang telah memberikan ruang untuk penerbitan artikel ini. Semoga artikel ini dapat memberikan kontribusi dalam pembelajaran terutama dalam kegiatan literasi kritis.

\section{Daftar Pustaka}

Arends, Richard I. 200I. Learning to Teach (Fifth Edition). New York: Mc.Graw-Hill.

Emzir. 2007. Metodologi Penelitian Pendidikan. Jakarta: Raja Grafindo.

Fitriyah, Mahmudah dkk. 2009. Keterampilan Berbahasa Indonesia. Jakarta: FITK Press.

Hidayat, Masnurul dkk. 2016. ”Efektivitas Model Pembelajaran Citizen Journalism: Melatih Keterampilan Mahasiwa Dalam Berpikir Kritis dan Kreatif." Jurnal Pendidikan, Vol.I, No. 2 Desember.

Hudaa, Syihaabul. 2017. "UKBI sebagai Suatu Cara Peningkatan Kesadaran Berbahasa Era Modern.” Prosiding, Ceramah Ilmiah Badan Pengembangan dan Pembinaan Bahasa.

Muliastuti, Liliana. 2017. Bahasa Indonesia Bagi Penutur Asing. Jakarta: Obor.

Mulyasa, E. 2004. Kurikulum Berbasik Kompetensi (KBK), Konsep, Karakteristik, dan Implementasi. Bandung: Remaja Rosdakarya.

Munir. 2008. Kurikulum Berbasis Teknologi Informasi dan Komunikasi. Bandung: Alfabeta.

https://edukasi.kompas.com/read/2010/04/28/16353 552/nilai.bahasa.indonesia.paling.rendah. Diakses Tanggal 20 April 2018. 